\title{
Microwave Assisted Alkaline Pretreatment and Microwave Assisted Enzymatic Hydrolysis of Palm Oil Mill Effluent (POME) for Optimum Fermentable Sugar Yield
}

\author{
SAIFUDDINNOMANBHAY* and REFALHUSSAIN \\ Centre of Renewable Energy, \\ University Tenaga Nasional, Jalan IKRAM-UNITEN-43000, Kajang, Selangor, Malaysia \\ saifuddin@uniten.edu.my
}

Received 13 June 2013 / Accepted 10 July 2013

\begin{abstract}
In the present study, a comparison of microwave assisted alkali pretreatment was tried using oil palm empty fruit bunch. The microwave assisted alkali pretreatment of POME using $\mathrm{NaOH}$, significantly improved the enzymatic saccharification of POME by removing more lignin and hemicellulose and increasing its accessibility to hydrolytic enzymes. Enzymatic hydrolysis of POME suspension by various amylolytic enzymes was investigated to reveal the potential coupling mechanism of Microwave Irradiation-Enzyme Coupling Catalysis (MIECC). It was shown that enzymatic hydrolysis of POME using typical enzymes may successfully was carried out at microwave condition. The MIECC resulted in increasing initial reaction rate by about 3 times. The results testify on specific activation of enzymes by microwaves and prove the existence of nonthermal effect in microwave assisted reactions. Low power microwave irradiation (100W) does not increase the temperature beyond $40{ }^{\circ} \mathrm{C}$ and hence denaturation of the enzyme is avoided. The present study has highlighted the importance of well controlled microwave assisted enzymatic reaction to enhance the overall reaction rate of the process.
\end{abstract}

Keywords: POME, Bioethanol, Enzymatic hydrolysis, Microwave assisted reaction, Non-thermal effects, Enzyme denaturation

\section{Introduction}

The development of the industrial and technological society together with the decreasing of oil reserves, the sharp increase in the cost of oil and the political instability of some crude oil producing countries, have been driving worldwide interest in searching for renewable energies to replace fossil fuels. Environmental issues such as global warming have demonstrated the vulnerability of the present sources for liquid fuel ${ }^{1}$. In this context, ethanol produced from biomass, the so called "bioethanol", has become a major energy carrier for a sustainable transportation sector. Bioethanol is an oxygenate fuel with an high octane number and it can be used as biofueleither in its pure state (E100) or blended with petrol in various proportions, such as E85, E95, E10 containing $85 \%, 95 \%$ and $10 \%$ of ethanol respectively ${ }^{2}$. Among these, E10 not requires anychange in engine ${ }^{3}$. Furthermore, due to the higher oxygen 
content, ethanol allows a better oxidation of the fuel and reduces $\mathrm{CO}$ and particulate emissions. Other advantages of ethanol versus gasoline are broader flammability limits, higher flame speeds, heat of vaporization and compression ratio and a shorter burn time $e^{1,4}$. Simultaneously, bioethanol is also building block for theproduction of several other chemicals, like acetaldehyde, ethane, ethylene, propylene, butadiene, carbon monoxide or hydrogen ${ }^{5-10}$. Today nearly $95 \%$ of hydrogen is produced from fossil-based materials such as methane and naphtha. Bioethanol as chemical reagent for hydrogen production could be a way to support hydrogen economy from a renewable and clean energy source ${ }^{7,8}$.

Palm-oil mill effluent (POME) is an abundant organic residue that is generated by palmoil mills during the process of extracting palm oil from fresh fruit bunches of oil palms. It has been estimated that POME contributes to about $30 \%$ of the total biochemical oxygen demand (BOD) load exerted on the Malaysian aquatic environment. Wastewater treatment facility is one of the most important components in the palm oil industry ${ }^{11,12}$. Specifically, the amount of POME generated is approximately $3.8 \mathrm{~m}^{3}$ for each ton of CPO produced ${ }^{13}$. POME is an acidic brownish colloidal suspension containing $95-96 \%$ water, $0.6-0.7 \%$ oil $(4000 \mathrm{mg} / \mathrm{L}) ; 4-5 \%$ total solids $(43,500 \mathrm{mg} / \mathrm{L})$ of which around $18,000 \mathrm{mg} / \mathrm{L}$ is suspended solids and with a very high biological oxygen demand (BOD) of $25,000 \mathrm{mg} / \mathrm{L}^{14,15}$. The POME solids consists mainly debris from palm fruit mesocarp which is lignocellulosic material. The POME has high amounts of carbohydrates $(29.55 \%)$, proteins $(12.75 \%)$, nitrogenous compounds and lipids with a considerable amount of cellulose and nontoxic minerals which can provide sufficient amount of nutrients and minerals favourable for microbial growth ${ }^{16,15}$. Recently, many processing technologies for converting POME into value added products have been realized using bioconversion process. In this process the rich organic residue is used as a medium where some microbial species grow, consume the organic components and at the same time, produce biomass and other valuable products ${ }^{17}$. These include carotenoid, which canbe further utilized for vitamins $\mathrm{A}$ and $\mathrm{E}$ (tocopherols) production $^{18}$, citric acid $^{19}$, biohydrogen ${ }^{20}$ and bioethanol ${ }^{21}$.

Current world bioethanol research is driven by the need to reduce the costs of production. For example, cheap feedstock, improvement in feedstock pretreatment, shortening of fermentation time, lowering the enzyme dosages, improving the overall starch hydrolysis and integration of the Simultaneous Saccharification and Fermentation (SSF) process could be the basis of cutting down production costs. Limited research has been done on bioethanol production by bioconversion of lignocellulosic and carbohydrate-based materials, especially $\mathrm{POME}^{21}$. Palm oil mill effluent has great potential as a substrate for acetone, butanol and bioethanol fermentation because it contains a mixture of carbohydrates. There are two forms of carbohydrates, insoluble and soluble carbohydrates, contained in POME. Ho et al., ${ }^{22}$ reported that the total soluble carbohydrate was low at concentration of about $3.9 \mathrm{~g} / \mathrm{L}$ POME; while the remaining of about $26 \mathrm{~g} / \mathrm{L}$ POME was the insoluble carbohydrate consisting of high molecular weight compounds such as cellulose, hemicellulose and starch. It is, therefore, necessary to hydrolyze the complex carbohydratein POME prior to processing it for bioethanol production. In this process, the direct bioconversion of POME into ethanol occurs in three steps. The first step is the delignification of lignocellulosic materials from their complex structure. The second step is the depolymerization of the carbohydrate polymers (cellulose and hemicellulose) intoreducing sugars (glucose, fructose, xylose etc.) using cellulolytic enzymes, followed by the third step, fermentation of sugars by yeast (S. cerevisiae) forbioethanol production. In biomass research in general, microwave irradiation has been used to extract oils from vegetable feedstock ${ }^{23}$, 
to pretreat biomass to benefit the subsequent enzymatic hydrolysis and fermentation ${ }^{24}$. Specific enzymes such as amylase, amyloglucoamylase and pulluanase are needed for hydrolyzing $\operatorname{starch}^{25,26}$. Tapai is a traditional fermented food popular in Malaysia and Indonesia. The inoculum is called ragitapai and is cheaply available in local market. Microorganisms found in the traditional ragitapai are moulds (Rhizopusoryzae, Amylomycesrouxii, Mucor sp. and Candida utilis) and yeasts (Saccharomyces cerevisiae, Saccharomycopsisfibuliger, Endomycopsisburtonii). The moulds are strong amylolytic $^{27}$. Microwave Irradiation-Enzyme Coupling Catalysis (MIECC) has also been proven as a useful tool for many enzymatic transformations in both aqueous and organic solutions ${ }^{28-30}$. It has been proposed that in case of low power of high-frequency electromagnetic field the nonthermal activation of enzyme may be observed ${ }^{31,32}$. Enzymatic hydrolysis of carbohydrate is a very important not only for bioethanol production but many other industrial process and study of amylolytic enzyme working at microwave conditions is of great importance from both the scientific and industrial interest. The objective of this study is to improve the bioethanol production from raw POME by using co-culturing approach and microwave irradiation. Microwave pretreatment will be carried on the POME suspension as some previous studies have shown that application of microwave irradiation pretreatment may significantly increase the conversion of carbohydrate materials to glucose $\mathrm{e}^{24,33}$. The objective of this study is to evaluate the efficiency of pretreatment and enzymatic hydrolysis by combination of microwave-alkali and MIECC on POME to enhance fermentable sugar production.

\section{Experimental}

All chemicals were purchased from Merck (Darmstadt, Germany). The chemical reagents were of analytical grade and used without further purification unless otherwise stated. Sodium hydroxide was purchased from Merck; acetic acid, sulfuric acid, calcium chloride, ammonium sulphate, magnesiumsulphate, anhydrous ethanol, calcium hydroxide and anhydrous glucose were purchased from J.T. Baker. Spectrophotometric analyses were performed using a Thermo Spectronic Helios $\alpha$ UV-Visible Spectrophotometer. Microwave treatments were carried out using a domestic microwave oven (Samsung, CE2877-N; Korea) with an operating frequency of $2450 \mathrm{MHz}$. The microwave oven provided microwave radiation at variable power levels of $100 \mathrm{~W}, 180 \mathrm{~W}, 300 \mathrm{~W}, 450 \mathrm{~W}, 600 \mathrm{~W}$ and $850 \mathrm{~W}$.

\section{Preparation of raw material}

Palm oil mill effluent was collected from East Oil Mill, Sime Darby Plantation, CareyIsland, Selangor, Malaysia. The fresh POME sample was collected during production of palm oil at a temperature between $80{ }^{\circ} \mathrm{C}$ and $90{ }^{\circ} \mathrm{C}$. After allowing it to cool, the POME was transferred to plastic container and tightly capped before transporting it to the UNITEN laboratory. At the laboratory POME was filtered through $5 \mathrm{~mm}$ sieve to remove heavy suspended particles. The containers were tightly capped and stored at $4.0{ }^{\circ} \mathrm{C}$ until further use. The POME sample having $4.0 \%(\mathrm{w} / \mathrm{v})$ of total suspended solid (TSS) was prepared on the basis of material balances ${ }^{19}$.

\section{Microorganisms and culture conditions}

Bacto-Peptone and yeast extract was purchased from BD Diagnostic Systems USA. The culture used was commercial ragitapai (which provides the amylolytic enzymes). It was obtained from the local market. Saccharomyces cerevisiae was used for the fermentation of hydrolyzed carbohydrate. Before using as inoculums, ragitapai $(10 \mathrm{~g})$ were aerobically 
propagated separately in $250 \mathrm{~mL}$ flasks containing $100 \mathrm{~mL}$ YEP broth media $\left(10\right.$ g.L $\mathrm{L}^{-1}$ yeast extract, 10 g.L $\mathrm{L}^{-1}$ Peptone and $5 \mathrm{~g} . \mathrm{L}^{-1} \mathrm{NaCl}$ ) at $37^{\circ} \mathrm{C}$ and $250 \mathrm{rpm}$ for $3 \mathrm{~h}$. The liquid media was autoclaved at $121^{\circ} \mathrm{C}$ for $15 \mathrm{~min}$ before the aerobic propagation.

\section{Microwave assisted alkaline pretreatment of POME}

Alkaline pretreatment of POME (for delignification) was carried out in $500 \mathrm{~mL}$ glass bottles with screw cap. The POME sample $(250 \mathrm{~mL})$ having $4.0 \%(\mathrm{w} / \mathrm{v})$ of total suspended solid was added with $1 \%(\mathrm{w} / \mathrm{v}) \mathrm{NaOH}$. With the cap of the bottles slightly loose, the samples were subjected to microwave treatment in a microwave oven. Output power was set at $180 \mathrm{~W}$ and the exposure time was at $10 \mathrm{~min}$. This power level was chosen since it allowed for sufficient lengths of pretreatment time without drastic volumetric losses of the liquid phase. After pretreatment reaction, the samples were filtered to separate the insoluble solid from the soluble fraction. The POME supernatant after the pretreatment was analyzed for TSS, reducing sugar, total carbohydrate and COD to observe the effectiveness of the pretreatment method compared to raw POME.

Reducing sugar contain in the POME supernatant was analysed using dinitrosalicylic (DNS) assay ${ }^{34}$, while total carbohydrate (TC) content was measured using phenol-sulphuric acid assay ${ }^{35}$ and the Chemical Oxygen Demand (COD) was measured using HACH reagents. Total Suspended Solid (TSS) was measured using standard APHA method ${ }^{36}$. Furfural was determined by using a spectrophotometer at $280 \mathrm{~nm}$ according to Aguilar et al., ${ }^{37}$ with furfuraldehyde as standard ${ }^{37}$. The results were compared with the values obtained from the raw POME

\section{Microwave assisted hydrolysis of pretreated POME}

As stated earlier, the second step in the process of bioethanol production is the depolymerization of the carbohydrate polymers (cellulose and hemicellulose) introducing sugars (glucose, fructose, xylose etc.) using cellulolytic enzymes. The microwave assisted enzymatic hydrolysis (saccharification) of pretreated POME was performed in the following manner. The pretreated POME supernatant (having 4.0\% (w/v) of total suspended solid was prepared as mentioned earlier. The pretreated POME supernatant $(250 \mathrm{~mL})$ was added with $10 \mathrm{~mL}$ of $10 \%$ ragitapai and then was subjected to microwave treatment (microwave oven, Samsung, CE2877- N, Korea) at $100 \mathrm{~W}$ for $3 \mathrm{~h}$ which consisted of a $1 \mathrm{~min}$ break after every 10 minutes microwave exposure. During the $1 \mathrm{~min}$ break, the sample mixture was removed from the microwave oven and mixed well by rapid swirling. After 1 min of mixing the sample was put back into the microwave oven and exposed to microwave irradiation for another $10 \mathrm{~min}$. The $10 \mathrm{~min}$ cycle was continued until the $3 \mathrm{~h}$ of incubation time was reached (about 18 cycles). After the $3 \mathrm{~h}$ hydrolysis with microwave treatment at $100 \mathrm{~W}$, the flasks were kept in a water bath at $50{ }^{\circ} \mathrm{C}$ for up to 5 $\mathrm{min}$. At the end of $5 \mathrm{~min}$, the supernatant was used to estimate the reducing sugar released for each flask. The reducing sugar was estimated by 3,5-dinitrosalicylic acid (DNS) method $^{34}$. The result expressed in milligram of reducing sugar per liter of pretreated POME (having $4.0 \%(\mathrm{w} / \mathrm{v})$ of total suspended solid). A standard curve was drawn by measuring the absorbance of known concentrations of glucose solutions at $570 \mathrm{~nm}$. All experiments were conducted in duplicate.

The control samples were not subjected to the microwave irradiation, but were incubated at $50{ }^{\circ} \mathrm{C}$ in a shaking water bath $(120 \mathrm{rpm})$ and incubated for $48 \mathrm{~h}$. The supernatant was analyzed for reducing sugars as before after the end of the incubation period. 


\section{Analytical methods}

Reducing sugar (measured as glucose) concentration in the samples was measured at several intervals. Samples were collected at every $2 \mathrm{~h}$ interval for the first $10 \mathrm{~h}$ which consist of 5 data and another 5 data at every $4 \mathrm{~h}$ for the next $20 \mathrm{~h}$. A total of 10 data were collected for the entire run of $30 \mathrm{~h}$. During the hydrolysis and fermentation, the content of reducing sugars, calculated as glucose, was determined by 3,5-dinitrosalicylic acid (DNS) method ${ }^{34}$. A standard curve was drawn by measuring the absorbance of known concentrations of glucose solutions at $570 \mathrm{~nm}$.

\section{Results and Discussion}

POME is a suitable substrate for bioethanol production because of its reasonably rich carbohydrate content. The yeast, S.cerevisiae, is non-amylolyticbut, a very good candidate for fermentation of sugar to ethanol ${ }^{26}$. Hence, pretreatment of POME is important to breakup lignocellulosic materials into simple sugar to be used by yeast during fermentation. Among the common pre-treatment methods used to pretreat lignocellulosic materials includes: physical (mechanical milling and extrusion), chemical (alkali, acid, ozonolysis and ionic liquids) physicochemical (steam explosion, hydrothermal, microwaves, ultrasound and $\mathrm{CO}_{2}$ explosion) and enzymatic treatment ${ }^{1,38,39}$. In this study alkaline pretreatment with low level microwave irradiation (100 W power output) was performed. Table 1 shows the characteristics of POME before and after the pretreatment. The POME mixture turned black after subjecting the raw POME to microwave assisted alkaline pretreatment. From the Table 1, it can be seen that there is a correlation between the amount of TSS reduced and the amount of total carbohydrate increased after pretreatment. This shows that, the alkaline can rupture the lignin seal to simple sugar ${ }^{40}$. The pretreatment using alkaline, improves recovery of sugars from hemicelluloses, facilitate the cellulose hydrolysis step and avoid the formation of inhibitors (furfural) for subsequent fermentation processes ${ }^{4,38,39}$. Alkaline treatment can also remove acetyl and the various acid substitutions on hemicelluloses that lower the accessibility of the enzyme to the hemicelluloses and cellulose surface ${ }^{41}$. The presence microwave irradiation helps in facilitating the conversion of carbohydrate polymers to reducing sugars. Microwave treatment helps in destroying the crystalline polymeric structure of carbohydrate and hence makes it easier for the conversion to reducing sugars.

The use of microwave radiation is a promising pretreatment process that utilizes thermal and non-thermal effects generated by microwaves in aqueous environments. Superiority of activating polysaccharides by microwave irradiation may be due to direct delivery of microwave energy to polysaccharides through molecular interactions with electromagnetic field. The vibration of polar molecules and the movement of ions results in the generation of heat and extensive collisions. These effects can accelerate chemical, biological and physical processes $^{42}$. From this study it was shown that the most efficient method for utilizing microwave radiation as a pretreatment process for POME was at lower power levels (100 W) in combination with dilute $\mathrm{NaOH}(1 \%)$. The choice of using $\mathrm{NaOH}$ as the medium is based on the fact that the effects of microwave-based processes depend on the polar characteristics of the system. $\mathrm{NaOH}$ has a much higher dipole moment compared to $\mathrm{H}_{2} \mathrm{SO}_{4}$ and deionized water, hence, makes $\mathrm{NaOH}$ a better choice for microwave assisted reactions ${ }^{42}$. Low level of MW power $(100 \mathrm{~W})$ was used in order to avoid the protein and other related structures from denaturation and to minimize the thermal effects of the process. In a study by Palav and Seetharaman $^{33}$ relatively short duration of the microwave treatment was also selected by them as appropriate for destroying the crystalline arrangement in carbohydrate polymers ${ }^{33}$. 
During delignification, the sodium hydroxide $(\mathrm{NaOH})$ breaks the ester bonds cross-linking lignin and xylan, thus increasing the porosity of biomass ${ }^{43}$. It was reported that during alkali pretreatment of wheat straw, with microwave assisted heating, lower sugars losses and higher hydrolysis rates were observed compared to alkali pretreatment with conventional heating method ${ }^{24}$.

Table 1. Comparison of some properties of POME after pre-treatment

\begin{tabular}{ccc}
\hline Parameters & Raw POME & Pre-treated POME \\
\hline Color & Dark brown & Black \\
TSS, g/L & 38.1 & 22.8 \\
Reducing sugar, g/L & 11.35 & 16.64 \\
Total Carbohydrate, g/L & 23.2 & 28.4 \\
Soluble COD, g/L & 59.0 & 58.6 \\
Furfural, g/L & 0.28 & 0.0 \\
\hline
\end{tabular}

\section{Microwave assisted hydrolysis of POME}

Hydrolysis of cellulosic biomass prior to fermentation to ethanol is a very important step because the yeast, S. cerevisiae, is non-amylolytic microbe. The hydrolysis (depolymerization) of carbohydrate polymers was done by using enzymes present in the ragitapai. This was done in order to provide sufficient amount of reducing sugar before the start of fermentation for production of bioethanol by S. cerevisiae. Two sets of experiments (microwave assisted hydrolysisand conventional hydrolysis) were performed. In microwave assisted hydrolysis and pretreated POME samples were subjected to microwave irradiation for 5 min $(100 \mathrm{~W})$ after addition of ragitapai. Low level of MW power was used (100 Watt) in order to avoid the enzyme denaturation and to minimize the thermal effects of the process. At this level, the temperature of the mixture was found to be in the range of $41^{\circ} \mathrm{C}-45^{\circ} \mathrm{C}$; which is crucial to avoid enzyme denaturation.

Table 2. Reducing sugar yield for microwave assisted hydrolysis and non-microwave hydrolysis of POME

\begin{tabular}{ccccc}
\hline Parameters & $\begin{array}{c}\text { Raw } \\
\text { POME }\end{array}$ & $\begin{array}{c}\text { Pre-treated } \\
\text { POME }\end{array}$ & $\begin{array}{c}\text { Microwave Assisted } \\
\text { enzymatic hydrolysis }\end{array}$ & $\begin{array}{c}\text { Non microwave } \\
\text { enzymatic hydrolysis }\end{array}$ \\
\hline $\begin{array}{c}\text { Reducing } \\
\text { Sugar, g/L }\end{array}$ & 11.35 & 16.64 & 38.3 & 23.8 \\
\hline
\end{tabular}

As shown in Table 2, at the end of the total $3 \mathrm{~h}$ incubation under microwave exposure $\left(100 \mathrm{~W}\right.$ output power; temperature $41{ }^{\circ} \mathrm{C}-45^{\circ} \mathrm{C}$ ) the highest yield of reducing sugar was found to be about $38.3 \mathrm{~g}$ per liter of pretreated POME. As for the non-microwave enzymatic hydrolysis, after the incubation period of $48 \mathrm{~h}$, the yield of reducing sugar was found to be $23.8 \mathrm{~g}$ per liter of pretreated POME. This shows that microwave assisted enzymatic hydrolysis enhances the yield of reducing sugar by about 3 fold as compared with the nonmicrowave enzymatic hydrolysis process.

Non-thermal effects or microwave effect has been observed in a number of microwave assisted catalytic or enzymatic reactions ${ }^{44}$. It has been proposed that at low power level of microwave irradiation, the significant contributor is the non-thermal effects, while the thermal effect plays only a minor role. The non-thermal effect brings about time-averaged drift motion of matter ${ }^{45}$ which provides the molecule collision under microwave irradiation extra driving force, which results in higher rate of reaction under microwave irradiation as long as the enzyme is not deactivated by microwave. Under low power level of microwave 
irradiation, the active site of the enzyme molecules may undergo conformational changes and the microwave energy can modulate the configuration of enzyme molecules by accelerating the molecular rotation, which can provide more chance to make the substrates fit to the enzyme per unit of time $\mathrm{e}^{44,31}$. It has also been suggested that microwave irradiation was able to decrease the activation energy of the reaction. In their work on bio-diesel production, Asakuma et al., ${ }^{46}$, have confirmed that preheating samples with microwave irradiation give the molecules a more flattened configuration, which improves reactivity due to the resultant lower dipole moment and lower activation energy.

\section{Conclusion}

This study examined the potential of microwave-based pretreatment and microwave assisted enzymatic reaction on POME. It was determined that the most efficient method for utilizing microwave radiation as a pretreatment process was at lower power levels in combination with dilute $\mathrm{NaOH}$. Ragitapai was chosen based on its ability toproduce glucose and ethanol yields from starch directly as presented previous by other researches, but with low yields ${ }^{47}$. The present study had also highlighted the importance of well controlled microwave assisted enzymatic reaction to enhance the overall reaction rate of the process. It should be noted that enzymatic hydrolysis of lignocellulose material using typical enzymes was successfully carried out under microwave condition. The effect of microwave irradiation strongly depends on; micro-wave power level-higher levels of MW may cause denaturation of the enzyme. The dominant factor in the microwave assisted reaction in this study may be treated as non-thermal effects. The MIECC or microwave assisted enzymatic reaction effects on reducing sugar production had shown a reaction rate increase of 3 fold.

\section{References}

1. Balat M, Balat $\mathrm{H}$ and $\mathrm{Oz} \mathrm{C,} \mathrm{Prog} \mathrm{Ene} \mathrm{Comb} \mathrm{Sci.,} \mathrm{2008,} \mathrm{34(5),} \mathrm{551-573;}$ DOI:10.1016/j.pecs.2007.11.001

2. Moon S K H M, Kim Y, Chung B and Choi G W, Biotechnol Bioprocess Eng., 2009, 14(5), 606-611; DOI:10.1007/s12257-008-0320-0

3. Balat M, Energy Source A, 2009, 31(13), 1160-1173;

DOI:10.1080/15567030801952201

4. Mussatto S I, Dragone G, Guimaraes P M R, Silva J P A, Carneiro L M, Roberto I C, Vicente A, Domingues L and Teixeira J A, Biotechnol Adv., 2010, 28(6), 817-830; DOI:10.1016/j.biotechadv.2010.07.001

5. Idriss H and Seebauer E G, J Mole Catal A: Chem., 2000, 152(1-2), 201-212; DOI:10.1016/S1381-1169(99)00297-6

6. Wong K M, Rahman N A, Aziz S and Sabaratnam V, Res J Microbiology, 2008, 6, 474-481.

7. $\quad \mathrm{Yu}$ C Y, Lee D W, Park S J, Lee K Y and Lee K H, Int J Hydrogen Ene., 2009, 34(7), 2947-2954; DOI:10.1016/j.ijhydene.2009.01.039

8. Lippits M J and Nieuwenhuys B E, Catal Today, 2010, 154(1-2), 127-132, DOI:10.1016/j.cattod.2010.03.019

9. Oakley J H and Hoadley A F A, Int J Hydrogen Ene., 2010, 35(16), 8472-8485; DOI:10.1016/j.ijhydene.2010.05.003

10. Song Z X, Takahashi A, Nakamura I and Fujitani T, Appl Catal A: Gen., 2010, 384(1-2), 201-205; DOI:10.1016/j.apcata.2010.06.035

11. Choo Y M, Malaysian Oil Sci Tech., 2007, 16, 12-20.

12. Saifuddin N and Fazlili S A, Am J Engg Appl Sci., 2009, 2(1), 139-146. 
13. Ma A N and Ong A S H, Biol Wastes, 1988, 23(2), 85-97;

DOI:10.1016/0269-7483(88)90066-3

14. Ma A N, Management of Palm Oil Industrial Effluents. In: Advances in Oil Palm Research, Basiron Y, Jalani B S and Chan K W, (Eds.), Bangi: Malaysian, Palm Oil Board, Ministry of Primary Industries Malaysia, 2000, 1439-1461.

15. Wu T Y, Mohammad A W, Jahim J M and Anuar N, Biotechnol Adv., 2009, 27(1), 40-52. DOI:10.1016/j.biotechadv.2008.08.005

16. Habib M A B, Yusoff F M, Phang S M, Ang K J and Mohamed S, Aquaculture, 1979, 158(1-2), 95-105; DOI:10.1016/S0044-8486(97)00176-2

17. Hipolito C N, Crabbe E, Badillo C M, Zarrabal O C, Mora M A M, Flores G P, Cortazar M H A and Ishizaki A, J Cleaner Prod., 2008, 16(5), 632-638; DOI:10.1016/j.jclepro.2007.02.005

18. Ahmad A L, Chan C Y, Abd Shukor S R and Mashitah M D, Chem Eng J., 2008, 141(1-3), 383-386; DOI:10.1016/j.cej.2008.03.005

19. Alam M Z, Jamal P and Nadzir M M, World J Microbiol Biotechnol., 2008, 24(74), 1177-1185; DOI:10.1007/s11274-007-9590-5

20. Chong M L, Abdul Rahman N A, Abdul Rahim R, Abdul Aziz S, Shirai Y and Hassan M A, Int J Hydrogen Energy, 2009, 34(17), 7475-7482;

DOI:10.1016/j.ijhydene.2009.05.088

21. Alam M Z, Kabbashi N A and Hussin, S N I S, J Ind Microbiol Biotechnol., 2009, 36, 801-808; DOI:10.1007/s10295-009-0554-7

22. Ho C C and Tan Y K, Water Res., 1983, 17(6), 613-618; DOI:10.1016/0043-1354(83)90229-4

23. Lucchesi M E, Chemat F and Smadja J, J Chromatogr A, 2004, 1043(2), 323-327; DOI:10.1016/j.chroma.2004.05.083

24. Zhu S, Wu Y, Yu Z, Chen Q, Wu G, Yu F, Wang C and Jin S, Process Biochem., 2006, 94(3), 437-442.

25. Nurachman Z, Kono A, Radjasa O K and Natalia D, Am J Biochem Biotechnol., 2010, 6(4), 300-306. DOI:10.3844/ajbbsp.2010.300.306

26. Jamai L, Ettayebi K, Yamani E L and Ettayebi M, Bioresour Technol., 2007, 98(14), 2765-2770; DOI:10.1016/j.biortech.2006.09.057

27. Gandjar I, Tapai from Cassava and Cereals, Proceedings of the 1st International Symposium and Workshop on Insight into the World of Indigenous Fermented Foods for Technology Development and Food Safety, Aug. 13-17, 2003, Kasetsart University, pp: 1-10; http://www.agriqua.doae.go.th/worldfermentedfood/I_10_Gandjar.pdf

28. Leadbeater N E, Stencel L M and Wood E C, Org Biomol Chem., 2007, 1052-1055; DOI:10.1039/B617544A

29. Yadav G D and Sajgure A D, J Chem Technol Biotechnol., 2007, 82, 964-970.

30. Roy I and Gupta M N, Curr Sci., 2003, 85, 1685-1693.

31. Yadav G D and Lathi P, Clean Technologies Environmental Policy, 2007, 9(4), 281-287; DOI:10.1007/s10098-006-0082-3

32. Saifuddin N, Raziah A Z and Farah H N, J Chem., 2009, 6, S485-S495; DOI:10.1155/2009/801756

33. Palav T and Seetharaman K, Carbohydr Polym., 2007, 67(4), 596-604; DOI:10.1016/j.carbpol.2006.07.006

34. Miller G L, Anal Chem., 1959, 31, 426-427; DOI:10.1021/ac60147a030

35. Fournier E, Current Protocols In Food Analytical Chemistry, Published Online: 1 AUG, John Wiley \& Sons, INC, 2001. 
36. (APHA), Standard Methods for the Examination of Water and Wastewater, $19^{\text {th }}$ Ed., Washington DC, USA: American Public Health Association, 1998.

37. Aguilar A, Ramirez J A, Garrote G and Vazquez M, J Food Eng., 2002, 55, 309-318; DOI:10.1016/S0260-8774(02)00106-1

38. Alvira P, Tomas-Pejo E, Ballesteros M and Negro M J, Bioresour Technol., 2010, 101(13), 4851-4861; DOI:10.1016/j.biortech.2009.11.093

39. Sannigrahi $\mathrm{P}, \mathrm{Pu} \mathrm{Y}$ and Ragauskas A, Current Opinion Environ Sustainability, 2010, 2(5-6), 383-393; DOI:10.1016/j.cosust.2010.09.004

40. Mosier N, Wyman C, Dale B, Elander R, Lee Y Y, Holtzapple M and Ladisch M, Bioresour Technol., 2005, 96(6), 673-686; DOI:10.1016/j.biortech.2004.06.025

41. Chang V S, Murlidhar N and Holtzapple M T, Appl Biochem Biotechnol., 1998, 74(3), 135-159; DOI:10.1007/BF02825962

42. Sridar V, Current Science, 1998, 74(5), 446-450.

43. Silverstein R A, Chen Y, Sharma-Shivappa R R, Boyette M D and Osborne J, Bioresour Technol., 2007, 98(16), 3000-3011;. DOI:10.1016/j.biortech.2006.10.022

44. Saifuddin N, Zhan L W and Ning K K X, Am J Appl Sci., 2011, 8(3), 217-229; DOI:10.3844/ajassp.2011.217.229

45. Kuhnert N, Angewandte Chemie International Edition, 2002, 41(11), 1863-1866; DOI:10.1002/1521-3773(20020603)41:11<1863::AID-ANIE1863>3.0.CO;2-L

46. Asakuma Y, Ogawa Y, Maeda K, Fukui K and Kuramochi H, Biochem Eng J., 2011, 58-59(15), 20-24; DOI:10.1016/j.bej.2011.08.003

47. Azmi A S, Ngoh G C, Maizirwan M and Masitah H, Afr J Biotech., 2010, 9(42), 7122-7127; DOI:10.5897/AJB10.933 